\title{
AN ANNOTATED CHECKLIST OF MOSQUITO FAUNA WITH VECTOR BIONOMICS IN NILGIRI HILLS, SOUTHERN INDIA
}

\author{
P. J. Bhuyan, J. Hiriyan, P. Chandrasekaran, C. Annadurai
}

1. Public Health Specialist. National Centre for Disease Control, Coonoor.

2. Senior Technical Officer, CRME, Madurai.

3. Technical Staff, National Centre for Disease Control, Madurai.

4. Technical Staff, National Centre for Disease Control, Madurai.

\section{CORRESPONDING AUTHOR:}

P. J. Bhuyan,

National Centre for Disease Control, Coonoor Branch,

Shanmugapriya, Brook Lands.

Coonoor - 643101, The Nilgiris, Tamil Nadu, India.

E-mail: pranabjyoti333@rediffmail.com

Ph: 00919442181442.

ABSTRACT: The earlier inventories of the mosquito fauna from Nilgiri hills are compiled and updated the faunal record. Out of 333 species belonging to 47 genera documented in India, 119 species of 21 genera are recorded from Nilgiri hills. 19 species of 4 genera having medical importance are being recorded from Nilgiri hills alone out of total 28 species belong to 5 genera recorded in India. Latter on during the course of dengue vector surveillance in between 2010 12 we have added two more species to the check list, An. Stephensi an area distribution record and Toxorhynchites species new under description. (Unpublished data, National Centre for Disease Control, Coonoor Branch). Overall 119 species belong to 21 genera are included in the check list. Evidently the area having richest mosquito fauna contributing more than $35 \%$ of the total Indian faunal record of which nineteen species belonging to four genera are considered to be having medical importance recorded from Nilgiri hills. Evidently the area having richest mosquito fauna contributing more than $35 \%$ of the total Indian faunal record which includes 19 species (>60\%) which are considered having medical importance. The bionomics of the prevailing vectors is discussed.

KEYWORDS: Species, Prevailing, Medical importance, An. stephensi, Toxorhynchites.

INTRODUCTION: There are about 3,500 species of mosquitoes world over globally, ranging in distribution from Sea Level to 3,600 meters altitudes. In India over 330 species including subspecies and varieties are catalogued and yet there may be more number of taxa awaiting description (Knight and Stone 1 Tewari et al 2. Of these about 28 species belonging to five genera are considered to be having medical importance like vectors / secondary vectors of malaria, lymphatic filariasis, Japanese encephalitis, dengue and chickungunya. (Table- 1). In order to have firsthand and correct information on the mosquito fauna it is considered inevitably indispensable to enumerate the biodiversity of mosquito in a given area and there is a need to update the faunal record. Earlier couple of inventories of the Indian mosquito fauna was compiled by Christophers 3 and Barraud 4, and they have recorded 28 species with certainty from Nilgiri hills. Subsequently, studies were carried out by Russel and Jacob 5, Wattal etal 6, Kalra and Wattal 7, Tewari etal 2, 8 and they have brought on record of an additional 89 species including 2 new species description Culex (Lophoceraomyia) raghavanii Rahman, Chowdhury and Kalra, Tewarius reubenae Tewari and Hiriyan 2, 9. Latter on during the course of dengue 
vector surveillance in between 2010 - 12 we have added two more species to the check list ie., An. Stephensi an area distribution record and Toxorhynchites species new under description. (Unpublished data, National Centre for Disease Control, Coonoor Branch). Overall 119 species belong to 21 genera are included in the check list. Of these nineteen species belonging to four genera which are considered to be having medical importance are recorded from Nilgiri hills. The bionomics of the above vector species is discussed.

The objective of the study is to update the checklist of mosquito fauna with vector bionomics in the Nilgiris, Tamil Nadu.

STUDY AREA: The Nilgiri hills (Fig-1) bordering Kerala, Karnataka and Tamil Nadu states in the part of Western Ghats lie between Latitude $110101 \mathrm{~N}$ and Longitude $76051 \mathrm{E}$ and situated at altitude ranging from 200 to 2600 Meters above Sea Level. The area receives good rain from both Southwest (July - September) and Northeast (October - December) monsoons. The prevailing average temperature is 5-280 $\mathrm{C}$.The area having diverse terrain feature with distinct ecological characteristic and falls under deciduous wet forest type. The vegetation consists of tropical thorny and mixed deciduous forest with only a few patches of subtropical evergreen forest. Afforestation, plantation of Teak, Eucalyptus, Acacia, and Pinus species are observed on the hill ranges. Extensive tea and coffee plantations are also seen present. The climatic conditions like temperature, humidity, rainfall and also the forest cover with diverse breeding habitats render the area highly suitable for mosquito breeding.

This study was carried out with the objective to update the checklist of mosquito fauna with vector bionomics. The earlier records of mosquito fauna from Nilgiri hills from 1933 to 1992 of various workers are compiled along with addition of our present records (NCDC unpublished data). In the course of vector surveillance carried out by NCDC, Coonoor branch during post monsoon of 2010-12, the probable breeding habitats of the dengue vectors around the human habitations in urban and semi urban situations were examined and collected the immature stage of mosquito, brought to the laboratory, reared to adult and identified the species. Identification of the species was following in principal the keys of Christophers 3 and Barraud 4 . To keep confirmative with the most recent and statutory amendment on the classification and nomenclature status of genera, subgenera and species recommendation of Harback and Kitching 10 Harback 11, Reinert 12, Reinert et al 13, and Reinert 14 have been followed.

\section{LIST OF MOSQUITO SPECIES RECORDED FROM NILGIRI HILLS:}

1. Anopheles (Anopheles) aitkenii James.

2. Anopheles (Anopheles) barbirostris, Van der Wulp.

3. Anopheles (Anopheles) barbumbrosus Strickland and Chowdhury.

4. Anopheles (Anopheles) crawfordi Reid.

5. Anopheles (Anopheles) gigas Giles.

6. Anopheles (Anopheles) insulaeflorum (Swellengrebel and Swellengrebel de Graaf.)

7. Anopheles (Anopheles) nigerrimus Giles.

8. Anopheles (Anopheles) nilgiricus Christophers.

9. Anopheles (Anopheles) peditaeniatus (Leicester).

10. Anopheles (Cellia) aconitus Doenitz.

11. Anopheles (Cellia) annularis Van der Wulp.

12. Anopheles (Cellia) culicifacies . Giles.

13. Anopheles (Cellia) elegans (James). 
14. Anopheles (Cellia) fluviatilis . James.

15. Anopheles (Cellia) Jamesii Theobald.

16. Anopheles (Cellia) jeyporiensis James.

17. Anopheles (Cellia) karwari (James).

18. Anopheles (Cellia) maculates Theobald.

19. Anopheles (Cellia) majidi Young and Majid.

20. Anopheles (Cellia) mirans. Sallum and Peyton.

21. Anopheles (Cellia) moghulensis Christophers.

22. Anopheles (Cellia) pallidus Theobald.

23. Anopheles (Cellia) splendidus koidzumi.

24. Anopheles (Cellia) stephensi Liston.

25. Anopheles (Cellia) subpictus Grassi.

26. Anopheles (Cellia) tessellates Theobald.

27. Anopheles (Cellia) vagus Doenitz.

28. Anopheles (Cellia) varuna Iyengar.

29. Anopheles (Cellia) willmori (James).

30. Aedes (Aedimorphus) alboscutellatus (Theobald).

31. Aedes (Aedimorphus) caecus (Theobald).

32. Aedes (Aedimorphus) jamesi (Edwards).

33. Aedes (Aedimorphus) pipersalatus (Giles).

34. Armigeres (Armigeres) subalbatus (Coquilett).

35. Armigeres (Leicesteria) annulitarsis Leicester.

36. Armigeres (Leicesteria) digitatus (Edwards).

37. Armigeres (Leicesteria) flavus ( Leicester).

38. Christophersiomyia annulirostris (Theobald). (= Aedes (Christophersiomyia) annulirostris)

39. Culex (Culex) barraudi Edwards.

40. Culex (Culex) edwardsi Barraud.

41. Culex (Culex)fuscocephala Theobald.

42. Culex (Culex) gelidus Theobald.

43. Culex (Culex) Jacksoni Edwards.

44. Culex (Culex) mimeticus Noe.

45. Culex (Culex) mimuloides Barraud.

46. Culex (Culex) mimulus Edwards.

47. Culex (Culex) murrelli Lien.

48. Culex (Culex) nilgiricus Edwards.

49. Culex (Culex) pseudovishnui Colless.

50. Culex (Culex) quinquefasciatus Say.

51. Culex (Culex) sitiens Wiedemann.

52. Culex (Culex) vishnui Theobald

53. Culex (Culex) whitmorei (Giles).

54. Culex (Culiciomyia)bailyi Barraud.

55. Culex (Culiciomyia) pallidothorax Theobald.

56. Culex (Eumelanomyia) brevipalpis (Giles).

57. Culex (Eumelanomyia) foliates Brug.

58. Culex (Eumelanomyia) malayi (Leicester). 
59. Culex (Eumelanomyia) pluvialis Barraud.

60. Culex (Lophoceraomyia) cinctellus Edwards.

61. Culex (Lophoceraomyia) flavicornis Barraud.

62. Culex (Lophoceraomyia) lasiopalpis Sirivanakarn.

63. Culex (Lophoceraomyia) mammilifer (Leicester).

64. Culex (Lophoceraomyia) minor (Leicester).

65. Culex (Lophoceraomyia) raghavanii Rahman, Chowdhury and Kalra.

66. Culex (Oculeomyia) bitaeniorhynchus Giles. (= Culex (Culex) bitaeniorhynchus)

67. Culex (Oculeomyia) infula Theobald. (=Culex (Culex) infula)

68. Downsiomyia albolateralis (Theobald). (=Aedes (Finlaya) albolateralis)

69. Fredwardsius vittatus (Bigot) (= Aedes (Stegomyia) vittatus)

70. Heizmannia (Heizmannia) chandi Edwards.

71. Heizmannia (Heizmannia) greenii (Theobald).

72. Heizmannia (Heizmannia) indica (Theobald).

73. Heizmannia (Heizmannia) metallica? (Leicester).

74. Heizmannia (Mattinglyia) discrepans (Edwards)

75. Kenknightua dissimilis (Leicester). (Aedes (Finlaya) dissimilis)

76. Lutzia (Metalutzia) fuscanas Wiedemann. (=Culex (Lutzia) fuscanas)

77. Lutzia (Metalutzia) halifaxii Theobald. (=Culex (Lutzia) halifaxii)

78. Lutzia (Metalutzia) raptor Edwards. (=Culex (Lutzia) raptor)

79. Lutzia (Metalutzia) vorax Edwards. (=Culex (Lutzia) vorax)

80. Malaya genurostris Leicester.

81. Malaya jacobsoni (Edwards).

82. Mansonia (Mansonioides)indiana Edwards.

83. Mansonia (Mansonioides) uniformis (Theobald).

84. Ochlerotatus (Bruceharrisonius) aureostriatus (Doleschall). (=Aedes (Finlaya) aureostriatus )

85. Ochlerotatus (Finlaya) albotaeniatis (Leicester). (=Aedes (Finlaya) albotaeniatis)

86. Ochlerotatus (Finlaya) chrysolineatus (Theobald). (=Aedes (Finlaya) chrysolineatus)

87. Ochlerotatus (Finlaya)gubernatoris (Giles). (=Aedes (Finlaya) gubernatoris)

88. Ochlerotatus (Finlaya) harveyi Barrraud. (=Aedes (Finlaya) harveyi)

89. Ochlerotatus (Finlaya) inquinatus Edwards. (=Aedes (Finlaya) inquinatus) 
90. Ochlerotatus (Finlaya) macdaugalli Edwards. (=Aedes (Finlaya) macdaugalli )

91. Ochlerotatus (Finlaya) oreophilus Edwards. (=Aedes (Finlaya) oreophilus)

92. Ochlerotatus (Finlaya) pseudotaeniatus (Giles). (=Aedes (Finlaya) pseudotaeniatus)

93. Orthopodomyia anopheloides (Giles).

94. Orthopodomyia flavithorax Barraud.

95. Paraedes menoni (Mattingly).

96. Stegomyia aegypti (Linnaeus). (=Aedes (Stegomyia) aegypti)

97. Stegomyia albopicta (Skuse). (=Aedes (Stegomyia) albopictus)

98. Stegomyia desmotes Giles. (=Aedes (Stegomyia) desmotes)

99. Stegomyia krombeini (Huang). (=Aedes (Stegomyia) krombeini)

100.Stegomyia pseudalbopicta Borel (=Aedes (Stegomyia) pseudalbopicta)

101.Stegomyia w-albus Theobald, (=Aedes (Stegomyia) w-albus)

102.Tewarius reubenae (Tewari and Hiriyan).

103.Tripteroides (Rachionotomyia) affinis (Edwards).

104.Tripteroides (Rachionotomyia) aranoides (Theobald).

105.Tripteroides (Rachionotomyia) serratus (Barraud).

106.Uranotaenia (Pseudoficalbia) bicolor Leicester.

107.Uranotaenia (Pseudoficalbia) luteola Edwards.

108.Uranotaenia (Pseudoficalbia) novobscura Barruad.

109.Uranotaenia (Pseudoficalbia) ohamai Tanaka, Mizusawa and Saugstad.

110.Uranotaenia (Pseudoficalbia) stricklandi Barraud.

111.Uranotaenia (Uranotaenia) annandalei Barraud.

112.Uranotaenia (Uranotaenia) kempestris Leicester.

113.Uranotaenia (Uranotaenia) orientalis Barraud.

114.Verrallina (Neomacleaya) agrestis (Barraud)

(=Aedes (Aedes) agrestis).

115.Verrallina (Neomacleaya) cautus (Barraud)

(=Aedes (Aedes) cautus).

116.Verrallina (Neomacleaya) pseudomediofasciatus (Tehobald).

(=Aedes (Aedes) pseudomediofasciatus)

117. Toxorhynchites (Toxorhynchites) minimus (Theobald).

118. Toxorhynchites (Toxorhynchites) splendens (Wiedemann).

119. Toxorhynchites (Toxorhynchites) new Species*

$>{ }^{*}$ Toxorhynchites species new under description. This species closely similar to Tx.edwardsi Barraud and Tx.splendens (Wiedemann) but differ in key characters. These specimens are deposited in the museum of Centre for Research in Medical Entomology (ICMR), Madurai, India with a request for detailed description.

$>$ Mosquitoes of medical importance in India (Table-1): 
> Anopheles barbirostris: Isolations of JE virus have been made from this species in Asansol and Bankura in West Bengal and Batai virus from Brahmapalli in Andhra Pradesh Reuben et al 15

$>$ Anopheles peditaeniatus: JE virus had been isolated from Anopheles hyricanus group (which include An. Peditaeniatus) in Asansol and Bunkura, West Bangal. Chakravarty et al.,16, Benerji et al.,17 and also JEV was isolated from An. Peditaeniatus in Mandiya, Karnataka. Mourya et al.18

$>$ Anopheles annularis: This belong to anuularis group consisting five species, four of these including An. annularis had been incriminated as vector of malaria. Harrison, 19.

$>$ Anopheles culicifacies: It is one of the most important malaria vector in rural and semi urban areas in India, being responsible for transmitting about $60-70 \%$ of malaria infections.

$>$ An. Culcifacies complex having five sibling species (A,B,C,D \& E) and members of this complex may differ in biologic characteristics influencing epidemiology and control of malaria Subbarao,20

$>$ Anopheles fluviatilsis: It is one of the most efficient vectors of malaria in India particularly in foothills (Rao ,21 Das et al 22 , Nagpal and Sharma 23,. It was abundant in Western Ghats ranges during pre DDT era where it was playing the role for hyperendemic malaria Russel and Jacob5, Tewari et al.,8

$>$ Anopheles mirans: This species belong to Anopheles leucosphyrus group and it was misidentified as An. elegans Sallum et al.,24 which was reported as vector of simian malaria from foot hills of Nilgiris.

> Anopheles stephensi: It is recognized as a major urban malaria vector Rao 21 and it was also considered as a vector in rural area Neogy and Sen 25,

$>$ Anopheles subpictus: JE virus has been isolated from this species in Karnataka, Kerala and Tamil Nadu. George et al.,26 ,Dhanda et al.,27 ; An. Subpictus appears to play the role of secondary vector of malaria. Panicker et al.28, and also it has been demonstrated to transmit JEV as a bridge vector. Thenmozhi et al.,29

$>$ Anopheles varuna: It has been found infected in nature with sporozoites Christophers 3 .

$>$ Culex fuscocephala: This species is an efficient vector of JE in Thailand Gould et al.30, . Isolations of JE virus from wild - caught mosquitoes have been made from that country and also in India Amerasinghe et al.,31, Reuben et al.,32.

$>$ Culex gelidus : This species is considered to be one of the most important vectors of JE in Sri Lanka, Thailand, Malaysia, Vietnam and Sarawak Gould et al.,33, Macdonald et al.,34, Peiris et al.,35. Relatively few isolates have been made in India Reuben et al.,15.

$>$ Culex vishnui Subgroup: Three species of this subgroup viz., Cx. tritaeniorhynchus, Cx. vishnui and $\mathrm{Cx}$. pseudovishnui are vectors of JE in India Reuben et al,32

$>$ Culex quinquefasciatus: It is well established as principal vector of nocturnal periodic bancroftian filariasis in South Asian countries including India, Myanmar, Malaya, Indonesia, Vietnam. Ragavan 36, Rajagopalan et al,37, 38, 39

$>$ Culex whitmorei: Several isolations of JE virus have been made from this species in India and Sri Lanka where it suspected to play a role as a secondary vector (Carey et al.,40 , Peiris et al.,35 , Philip Samuel et al., 41.

$>$ Mansonia Species: The Mansonia species are the vectors of Brugia malayi filariasis in India. Ragavan 36 . In a recent outbreak of JE in Kerala, isolation of JE virus was made from Ma.uniformis and Ma.indiana Dhanda et al.,27. 
$>$ Stegomyia aegypti: A highly anthropophilic, daytime biting mosquito species and principal vector of dengue in Southeast Asia including India where it was responsible for major epidemics Gubler and Kuno 42, WHO,SEARO 43,. Various strains of dengue and chickungunya viruses have been isolated from this species in southern India (Reuben et

$>$ al., 15, Tewari et al,44 including demonstration of vertical transmission of dengue virus Thenmozhi et al., 45 .

$>$ Stegomyia albopicta :It is typically rural dengue vector and causing mild or asymptomatic dengue virus infection in humans Haweley 46. A strain of dengue virus (DEN - 4) was isolated from this species in India Reuben et al.,15 and various strains of dengue, Reovirus -3 and Tembusu virus have been isolated from Southeast Asian countries Huang 47 . Dengue virus (DEN - 2) was isolated from rural areas of Vellore district in South India where it was considered as a secondary vector Tewari et al.,44. In Kerala (South western India) it was abundantly found biting man in outdoors near human habitation. Recently resurgent of dengue reported where DEN 2 was isolated from this species Tyagi et al.,48.

RECENT RECORDS FROM NILGIRIS: The Nilgiri hills having the richest have a rich mosquito fauna contributing over $35 \%$ of the total Indian fauna along with the prevalence of 19 species which are considered to be having medical importance and yet the hill ranges are free from any of the mosquito borne diseases. However, once Gudalur taluk was considered as malaria endemic area and Anopheles fluviatilis was responsible for the transmission of malaria. After the DDT era during 1940s malaria incidence was declined and the vector Anopheles fluviatilis is considered almost vanished extinct species thereafter. The other malaria vectors Anopheles culicifacis and Anopheles stephensi are prevailing prevalent in very low density. Tewari etal.,8. An. Stephensi an area distribution record as so far it has not been recorded from Nilgiri hills and this is the first report from high altitude area above 2400 MSL, Coonoor. Presently most of the vectors or the species with epidemiological implication are prevailing in very low density. The reason of non endemicity can be attributed to the prevailing ecological conditions such as very low density of vectors, the biologic characteristic of the vector with little influencing epidemiology, low temperature (The area experiencing the average temperature range is 5250C.), lesser man mosquito contact. (Most of the mosquito ceases to bite belowdo not bite at temperatures below $160 \mathrm{C}$. It is also understood from laboratory based study on vector biology that delimiting factors of dengue incidence ie.is, poor percentage of egg hatchability, prolonged period in larval development, poor survival rate in larval stages. All these can be considered a common factor for delimiting the mosquito borne diseases. However Stegomya albopicta which is the dominant species, wide spread throughout the hill ranges accounting for over $65 \%$ of the total mosquito specimens recorded. (Unpublished data, NCDC, Coonoor branch).The surrounding areas of the Nilgiri hills particularly parts of Kerala and Tamil Nadu states are often experiencing with dengue infection and Stegomyia albopicta is considered the lone epidemic vector of dengue in Kerala state. Stegomyia albopicta has the ability to propagate and establish its population displacing Stegomyia aegypti, the domesticated mosquito from its domain. Evidently it has been observed that Stegomyia albopicta is now fast approaching its establishment nearer to human habitation in peri-urban and urban situations in Nilgiris. (Unpublished data, NCDC, Coonoor branch). Nilgiri hills due to its tourist importance having a large number of floating population from all over the country. When the suitable ecological conditions are in place with susceptible human population and vector abundance along with the 
presence of both vector species, favour the probable increased risk of dengue outbreaks. Hence a constant vigil needs to be undertaken to monitor the dengue incidence in Nilgiri hills. Though it is unpublished data but presented these findings in the 6th Conference of Medical Arthropodology organized by the CRME, (ICMR), Madurai, (TN), from 18th \& 19th,October,2012 \& the 57th Annual Conference of IPHA, 2013 at Kolkata from 1st to 3rd Feb, 2013.

ACKNOWLEDGEMENT: Thanks are due to Shriyuts N. Muthukrishnan, T.N. Muralidharan, J. Sankaran and Mrs. Vijaylakshmi, NCDC, Coonoor Branch for their excellent assistance in the laboratory and field.

\section{REFERENCES:}

1. Knight KL and Stone A (1997): A catalog of the mosquitoes of the world (Diptera; Cilicidae) College Park, MD: The Thomas Say Foundation, Entomological Society of America. II edition. 6, 1-611.

2. Tewari SC, ,Ayanar $\mathrm{K}$ et al (2007): An annotated checklist of Indian mosquito species CRME Mosquito Museum 1,1-124.

3. Christophers SR (1933): Family Culicidae. Tribes Anophelini. The fauna of British India, including Ceylon and Burma 0 Diptera, Taylor and Francis, London. 4, 1-271.

4. Barraud PJ (1934): Family Culicidae, Tribes Megarhinini and Culincini, The fauna of British India, Including Ceylon and Burma- Diptera Taylor and Francies, London. 5, 1-463.

5. Russell PF and VP Jacob (1942): On the epidemiology of malaria in the Nilgiris District, Madras Presidency. J. Mal. Inst. Ind, 4, 349-392.

6. Wattal BL, NL Kalra and R Rajagopal (1962). A study of I Anopheles barbirostris Van der Wulp in the collection of the Malaria Institute of India with first record of A. barurnbrosus Strickland and Chowdhury and A. vanus Walker in India. Indian J Malariol, 16, 63-74.

7. 7.Kalra NL and BL Wattal (1962): A note on Anopheles leucosphyrus Doenitz adults in the collection of the Malaria Institute of India with distribution records of A.balbacensis balbacensis Baisas and A. elegans James in India. Bull Nat. Soc.Ind Mal. Mosq. Dis, 10, 159-167.

8. Tewari SC, Hiriyan J , Reuben R (1987): Survey of the Anophelene fauna of the Western Ghats in Tamil Nadu, India. Indian J Malariol 24, 21 - 28.

9. Tewari SC and Hiriyan J (1992) Description of two new species of Aedes (Diceromyia) from South India (Diptera: Culicidae). Mosq Syst 24, 154-175

10. Harbach RE and Kitching I (1998): Phylogeny and classification of the Culicidae (Diptera). Syst Entomol 23, 327-370.

11. Harbach RE (2004): The classification of genus Anopheles (Diptera: Culicidae): a working hypothesis of phylogenetic relationships B Entomol Res 94, 534-533.

12. Reinert JF (2000): New classification for the composite genus Aedes (Diptera: Culicidae: Aedini), elevation of subgenus Ochlerotatus to generic rank, reclassification of the other subgenera and notes on certain subgenera and species J Am Mosq Control Assoc 16, 175-188.

13. Reinert JF, Harbach RE and Kitching I (2004): Phylogeny and classification of Aedini (Diptera Culicidae), based on morphological charectors of all life stages. Zool J Linn Soc $142,289-368$. 
14. Reinert JF (2006): Tewarius Reinert, a new genus of Aedini (Diptera; Culicidae). Proc Entomol Soc Wash 108, 639-645.

15. Reuben R, Kaul HN and Soman RS(1988): Mosquitoes of arboviral importance in India. Mosq Borne Dis Bull. 5, 48 - 54.

16. Chakravarty SK , Chakravarty AK,Mukherjee KK et al (1981): Isolation of Japanese encephalitis (JE) virus from Mansonia annulifera species of mosquitoes in Assam. Bull Cal Sch Trop Med 129, 3.

17. Benerji K, P.V.M.Mahadev,M.A.Ilkal et al (1979): Isolation of Japanese encephalitis virus from mosquitoes collected in Bankura district (West Bengal) during October, 1974 to December 1975.Indian J. Med. Res. 69: 201-205.

18. Mourya DT, Ilkal MA, Mishra AC et al. (1989)Isolation of Japanese encephalitis virus from mosquitoes collected in Karnataka state, India during 1985 - 1987. Trans R Soc Trop Med Hyg 83: 550, 1989.

19. Harrison BA, Rattanarithikul R, Peyton EL et al (1991): Taxonomic changes, revised occurance records and notes on the Culicidaeof Thailand and Neighbouring countries. Mosq Syst 22, $196-227$.

20. Subbarao KS (1998): Anophelene species complexes in Southeast asia. Tech Publ WHO, SEARO No. 18.

21. Rao TR(1984): In: The Anopheline of India (Revised Edition), Malaria Research Centre, Indian Council of Medical Research, New Delhi, 1-518.

22. Das BP, Rajagopal R and Akiyama J (1990): Pictorial Key to the species of Indian Anopheline mosquitoes. J Pure App Zool 2, 131-162.

23. Nagpal BN and Sharma VP (1995): Indian Anophelines, Oxford and IBH Publishing Co. Pvt. Ltd, New Delhi

24. 24.Sallum MAM, Preton EL and Wilkerson RCl (2005): Six new species of the Anopheles leucosphyrus group, with reinterpretation of An.elegans and vector implications, Med vet Entomol 19, - 199.

25. Neogy BP and Sen AK (1962): Anopheles stephensi as a malaria carrier in rural Bengal. Indian J Malariol 16, 81 - 85.

26. George S, George JPand Rao JA (1987): Isolation of Japanese encephalitis and West Nile viruses from mosquitoes collected in Kolar district of Karnataka state during 1977 - 79. Indian Journal of Med Res. 85, 255.

27. Dhanda V,Thenmozhi V,Kumar NO et al (1997): Virus isolation from wild caught mosquitoes during Japanese encephalitis outbreak in Kerala in 1996. Indian Journal of Med Res 106,4.

28. Panicker KN, Geetha Bai M, Bheema Rao US et al (1981) Anopheles subpictus, vector of malaria in coastal villages of Southeast India. Current Science 50, 694-695.

29. Thenmozhi V, Rajendran R, Ayanar K et al, (2006): Long - term study of Japanese encephalities virus infection in Anopheles subpictus in Cuddalore district, Tamil Nadu, South India.Tropical Medicine and International Health. 11: 288 - 93.

30. Gould DJ, Edelman RA,Grossman A et al (1974): Study of Japanese encephalitis virus in Chiangmai Valley, Thailand. IV. Vector studies. An J Epidemiol 100, 49-56.

31. Amerasinghe FP , J.S.M Peiris, S.H.P.P Karunaratne et al(1988): Epidemiology of the 1987 Japanese encephalitis outbreak in Anurathapura area. II.Entomological aspexts. Proc Sri Lanka Med Assoc 101, 22-23. 
32. Reuben R, Tewari SC, Hiriyan J et al (1994): Illustrated keys to species of Culex(Culex) associated with Japanese encephalitis in Southeast Asia (Diptera: Culicidae)

33. Gould DJ, Barnett HC and Suyemoto W (1962): Transmission of Japanese encephalitis virus by Culex gelidus Theobald. Trans R Soc Trop Med Hyg 56, 429435.

34. Macdonald WW, Smith CEG,Dawson PS (1967): Arbovirus infection in Sarawak: further observations on mosquitoes. J Med Entomol 4, 146-157.

35. Peiris JSM,Amerasinghe FP and Arnagiri CK (1993): Japanese encephalitis in Sri Lanka: Comparison of vector and virus ecology in different agro-climate areas. Trans R. Soc Trop Med Hyg 87, 541-548.

36. Raghavan NGS (1961): The vectors of human infections in Wuchereria species in endemic areas and their biology. Bull WHO 24, 177-195.

37. Rajagopalan PK, Kazmi SJ and Mani TR (1977): Some aspects of transmission of Wuchereria bancrofti and ecology of the vector Culex pipiens fatigans in Pondicherry. Indian J Med Res 66, 200-215.

38. Rajagopalan PK, Geetha Bai M and Arunachalam N (1981): Age-determination of man-biting population of Culex pipiens fatigans with particular reference to transmission of Wuchereria bancrofti in Pondicherry. Indian J Med Res 73, 739-745.

39. Rajagopalan PK, Das PK, Subramanian S et al (1989): Bancroftian filariasis in Pondicherry, South India II. Epidemiological evaluation of the effect of vector control. Epidemiol Infect 103, 693-702.

40. Carey DE, R.Reuben and R.M.Myers (1968): Japanese encephalitis studies in Vellore, South India part I. Virus isolation from mosquitoes Indian J Med Res 56, 1309 1318.

41. Philip Samuel P, Hiriyan J, Gajanana A (2000): Japanese encephalitis virus infection in mosquitoes and its epidemiological implications. ICMR Bulletin 30(4), 37-43.

42. Gubler DJ and Kuno G (1997): Dengue and dengue hemorrhagic fever. New York: CABI Publishing, 1-478.

43. World Health Organization SEARO (1999): Prevention and control of dengue and dengue hemorrhagic fever - comprehensive guidelines: WHO - Regional Office for South - East Asia New Delhi. No.29, 1-134.

44. Tewari SC, Thenmozhi V, Katholi CR et al (2004): Dengue vector prevalence and virus infection in a rural area in South India. Trop Med Int Health 9, 499 - 507.

45. Thenmozhi V,Tewari SC, Manavalan R et al (2000): Natural vertical transmission of dengue viruses in Aedes aegypti in southern India. Trana R Soc Trop Med Hyg 94, 507.

46. Hawley WA (1998): The biology of Aedes albopictus. J Am Mosq Control Assoc. Suppl 1,1-39.

47. Huang YM (1979): Contribution to mosquito fauna of southeast Asia XI. The subgenus Stegomyia of Aedes in the Oriental region with Keys to the species (Diptera: Culicidae) Cont Amer Ent Inst 15, 1-79.

48. Tyagi BK, Hiriyan J, Philip Samuel P et al (2006): Dengue in Kerala: A critical review. Indian Council of Medical Research Bulletin 36, 13 - 22. 
Table: 1- LIST OF MOSQUITO SPECIES OF MEDICAL IMPORTANCE IN INDIA.

\begin{tabular}{|c|c|}
\hline Vectors & Diseases \\
\hline Anopheles barbirostris * & Malaria, Japanese encephalitis \\
\hline Anopheles peditaeniatus* & Japanese encephalitis \\
\hline Anopheles annularis * & Malaria \\
\hline Anopheles culicifacies* & Malaria \\
\hline Anopheles fluviatilis * & Malaria \\
\hline Anopheles minimus & Malaria \\
\hline Anopheles mirans * & Simian malaria \\
\hline Anopheles philippinensis & Malaria \\
\hline Anopheles stephensi * & Malaria \\
\hline Anopheles subpictus * & Malaria, Japanese encephalitis \\
\hline Anopheles sundaicus & Malaria \\
\hline Anopheles varuna * & Malaria \\
\hline Culex fuscocephala * & Japanese encephalitis \\
\hline Culex gelidus * & Japanese encephalitis \\
\hline Culex pseudovishnui * & Japanese encephalitis \\
\hline Culex quinquefasciatus * & Wuchereria bancrofti filariasis \\
\hline Culex tritaeniorhynchus & Japanese encephalitis \\
\hline Culex vishnui * & Japanese encephalitis \\
\hline Culex whitmorei * & Japanese encephalitis \\
\hline Culex bitaeniorhynchus & Japanese encephalitis \\
\hline Culex epidesmus & Japanese encephalitis \\
\hline Culex infula & Japanese encephalitis \\
\hline Mansonia annulefera & Brugia malayi filariasis \\
\hline Mansonia Indiana * & Japanese encephalitis \\
\hline Mansonia uniformis * & Brugia malayi filariasis, Japanese encephalitis \\
\hline Stegomyia aegypti * & Dengue, Chikungunya \\
\hline Stegomyia albopicta * & Dengue, Chikungunya \\
\hline Downsiomyia nivea & Wuchereria bancrofti filariasis \\
\hline
\end{tabular}


Fig:1 Map showing study area in Western Ghats

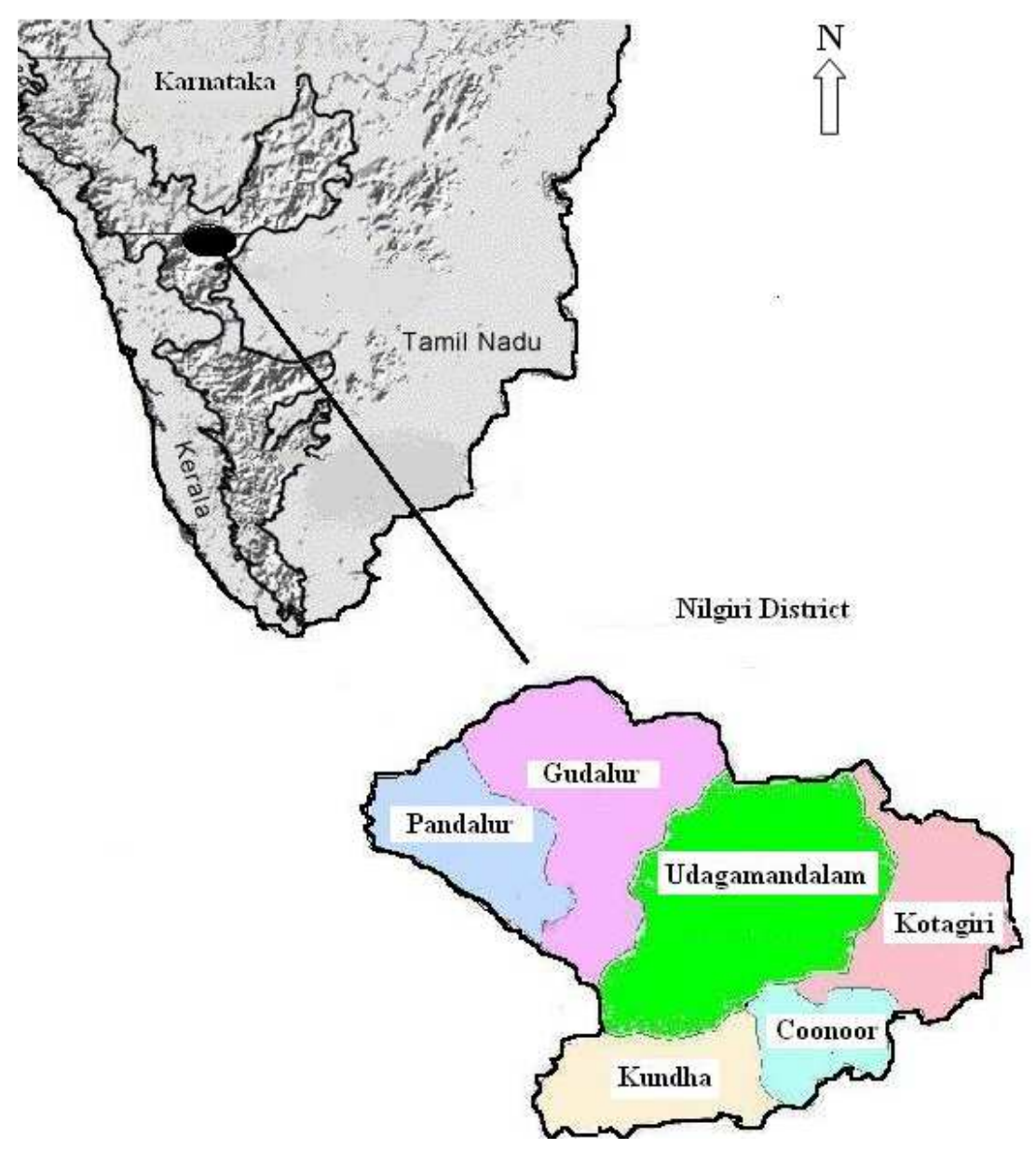

1. Map showing study area in Western Ghats.

2. Map of the Nilgiri district 